\title{
Body weight and eating habits of school students in Kore sub-district of Erbil: A cross-sectional study
}

\section{Abstract}

Background and objective: The prevalence of obesity is increasing worldwide at an alarming rate in both developing and developed countries. The aim of this study was to assess the weight of a sample of school students and its association with their eating habits and life-style practices.

Methods: This cross-sectional study was conducted on 477 students selected from four intermediate and secondary schools in Kore sub-district in Erbil, Iraq. Data on the students' eating and drinking habits, in addition to weight, height, smoking and other life style habits were collected through a self- administered questionnaire.

Results: The prevalence of overweight and obesity (categorized into one group) was more common among female students than male students $(19.9 \%$ and $11.8 \%$, respectively) with a significantly statistical difference $(\mathrm{OR}=0.536 ; 95 \% \mathrm{Cl}, 0.321-0.894, \mathrm{P}=0.017)$. Sleeping hours/night was also significantly associated with overweight and obesity, where sleeping less than 6 hours and between 6 and 8 hours was significantly associated with overweight and obesity $(P=0.004$ and 0.001 , respectively). There was no statistical association between overweight and obesity and all reported eating habits including breakfast, lunch, fried food, vegetables, salads and fruit juice intake, in addition to intake of crisps and cakes, energy providing drinks, soft drinks, and of milk and dairy products.

Conclusion: The prevalence of overweight and obesity among the study sample was low and there was no significant association with the eating habits and life-style practices, apart from those sleeping less than eight hours/nigh.

Keywords: Eating habits, BMI, Life-style practices, School students, Obesity.

\section{Introduction}

The prevalence of obesity is increasing worldwide at an alarming rate in both developing and developed countries. Obesity has become a serious epidemic health problem, estimated to be the fifth leading cause of mortality at global level. ${ }^{1}$ It is well known and documented that diet and nutrition play important role in maintaining health and preventing diseases. Decrease in morbidity and mortality associated with lifestyle diseases may be achievable if satisfactory nutritional habits are adopted in early life and maintained in the long term. During adolescence, young people are assuming responsibility for their own eating habits, health attitudes and behaviors. In fact, attitudes play an important role in the adoption and maintenance of a variety of health and nutritional habits. ${ }^{2}$ Most of the Middle East countries have experienced a nutritional transition in food choices during the past years from the typical Mediterranean diet into the fast food pattern. Dietary habits of young adults are affected by the fast-food market. Consequently, overweight and obesity are increasingly observed among the young. Obesity in combination with unhealthy life style, such as smoking and physical inactivity, may increase the risk of chronic diseases. ${ }^{3}$ Recent publications predicted that the severity of obesity will continue to rise and its prevalence will increase globally. Many studies demonstrated that

* Department of Community Medicine, College of Medicine, Hawler Medical University, Erbil, Iraq 
overweight children tend to become overweight and obese adults. Also, there is substantial evidence that childhood obesity is a major risk factor for adulthood morbidity, especially cardiovascular disease. Therefore, in recent years, the prevention of obesity in childhood has been considered crucial for the prevention of lifestyle-related diseases in adults. ${ }^{4}$ During the last few decades, most of developing countries including Kurdistan region had experienced rapid socio-cultural changes caused by the accelerating economy especially in petroleum producing countries. This was associated with major changes in the food choices and eating habits, which progressively became more and more "westernized". Since people used to move from home kitchen to fast foods, in addition to wide prevalence of dried snacks (potato crisp, biscuits, nestles, .etc). Such "a nutritional transition" has been claimed for the rising rates of overweight and obesity, which was recently observed among Iraqi citizens especially the growing age groups from preschool aged children to university students. To the researchers' knowledge, there is limited research on this important social problem in Iraq and Kurdistan region. ${ }^{5,6}$ This study was carried out, therefore, to assess the weight of school students and its association with their eating habits and life-style practices in Kore sub-district of Erbil Governorate.

\section{Methods}

This cross-sectional study was conducted in the sub-district of Kore of Erbil Governorate among the $7^{\text {th }}-11^{\text {th }}$ year students of the public intermediate and secondary schools from the $1^{\text {st }}$ to $25^{\text {th }}$ May 2013. Kore is a town in Erbil Governorate in Iraq. It is a sub- district on the main way to Saqlawa district; it is a semi-urban area with approximately 12,000 people, including the surrounding villages. It is 35 kilometers to the northeast of Erbil, at the bottom of Safeen Mountain. The town is inhabited by Kurds. It is one of the agricultural area in north of Erbil governorate. The sub-district had four intermediate and secondary schools for boys and girls with 680 students. The four selected schools from the sub-district were approached after getting official permission from the related educational authority. All the school students were approached through their school principals and a convenience sample of 500 students from the selected schools was obtained. The twelfths grade students were excluded because they had finished their academic year at the time of data collection and were released home, in addition to those who were not ready to fill in the questionnaire. The questionnaire, which was quoted from other studies and the standard Youth Risk Factor Behaviour Survey (YRBS) questionnaire, ${ }^{2,7}$ included questions on the eating and drinking habits of the students, in addition to their weight, height, smoking and other life style practices. Five hundred students from $7^{\text {th }}$ to $11^{\text {th }}$ grades were selected, after getting verbal consent from them; a self- administered questionnaire in Kurdish language was distributed to students by well-trained teaching staff from the area, who instructed students on how to fill out the questionnaire properly. Body mass index (BMI) calculated to assess students' weight status; it was categorized into four groups, ${ }^{8}$ underweight below 18.5 $\mathrm{kg} / \mathrm{m} 2$, normal weight between 18.5-24.9 $\mathrm{kg} / \mathrm{m} 2$, overweight between $25.0-29.9 \mathrm{~kg} /$ $\mathrm{m} 2$ and obese $30.0 \mathrm{~kg} / \mathrm{m} 2$ and above. For the purpose of data analysis; overweight and obesity was categorized into one main group to compare it with those who having normal weight. The data managed through the statistical package for social sciences software (version 18.0), using binary logistic regression test. A $P$ value of $\leq 0.05$ was considered statistically significant.

\section{Results}

A total of 477 out of 500 students from different grades participated in the current survey, with a response rate of $95.4 \%$. Their age ranged between 12 and 
26 years with a mean \pm SD of $15.15 \pm$ 1.96 years. Males constituted $46.3 \%$ of the sample, with a male to female ratio of $0.87: 1$. Slightly more than two-thirds $(67.7 \%)$ of the students were in the intermediate schools, and $32.3 \%$ in the secondary schools. The prevalence of overweight and obesity was more common among female students than male students $(19.9 \%$ and $11.8 \%$, respectively) with a significantly statistical difference
(OR=0.536; $95 \% \mathrm{Cl}, 0.321-0.894, \mathrm{P}=$ $0.017)$. Overweight and obesity was more common among those less than 18 years $(16.7 \%)$ than among those $\geq 18$ years of age $(12.3 \%)$, with no statistical significant difference $(P=0.401)$. On the other hand, $16.4 \%$ of intermediate school students and $15.6 \%$ of secondary school students were overweight and obese, with no statistical significant association $(P=0.819)$. Details are shown in Table 1.

Table 1: Association between body mass index categories and socio-demographic characteristics of the students, using binary logistic regression.

\begin{tabular}{llcllll}
\hline Variables & $\begin{array}{l}\text { Non- obese } \\
(\mathbf{4 0 0})\end{array}$ & $\begin{array}{l}\text { Obese }^{*} \\
(\mathbf{7 7})\end{array}$ & OR (95\% CI) & P value \\
& No. & $(\%)$ & No. & $(\%)$ & & \\
& & & & & & \\
\hline Age & 350 & $(83.3)$ & 70 & $(16.7)$ & $1.429(0.622-3.281)$ & \\
$<18$ & 50 & $(87.7)$ & 7 & $(12.3)$ & $1.00($ ref $)$ & 0.401 \\
$>18$ & & & & & &
\end{tabular}

\section{Sex}

Male

195

(88.2) $\quad 26$

(11.8) $\quad 1.00$ (ref)

Female

205

$(80.1)$

51

(19.9)

$0.536(0.321-0.894)$

0.017

\section{School type}

$\begin{array}{llllll}\text { Intermediate } & 270 & (83.6) & 53 & (16.4) & 0.940(0.556-1.591) \\ \text { Secondary } & 130 & (84.4) & 24 & (15.6) & 1.00 \text { (ref) }\end{array}$

*Including overweight 
There was no statistical association between overweight and obesity and all reported eating habits including breakfast, lunch, fried food, vegetables, salads and fruit juice intake, in addition to intake of crisps and cakes, energy providing drinks, soft drinks, and of milk and dairy products (Table 2).

Table 2: Association between body mass index categories and eating habits of the students, using binary logistic regression.

\begin{tabular}{|c|c|c|c|c|c|c|}
\hline \multirow[t]{2}{*}{ Variables } & \multicolumn{2}{|c|}{$\begin{array}{l}\text { Non- obese } \\
(400)\end{array}$} & \multicolumn{2}{|c|}{$\begin{array}{l}\text { Obese* } \\
\text { (77) }\end{array}$} & \multirow[t]{2}{*}{$\mathrm{OR}^{* *}(95 \% \mathrm{Cl})$} & \multirow[t]{2}{*}{$P$ value } \\
\hline & No. & $(\%)$ & No. & $(\%)$ & & \\
\hline \multicolumn{7}{|l|}{ Breakfast intake } \\
\hline Frequent $^{* * *}$ & 331 & $(85.1)$ & 58 & $(14.9)$ & 1.00 (ref) & \\
\hline Infrequent ${ }^{* * * *}$ & 69 & $(78.4)$ & 19 & $(21.6)$ & $0.650(0.360-1.173)$ & 0.152 \\
\hline \multicolumn{7}{|l|}{ Lunch intake } \\
\hline At home & 349 & $(84.9)$ & 62 & $(15.1)$ & 1.00 (ref) & \multirow[b]{2}{*}{0.138} \\
\hline Outside & 51 & $(77.3)$ & 15 & $(22.7)$ & $0.608(0.315-1.173)$ & \\
\hline \multicolumn{7}{|l|}{ Fried food intake } \\
\hline Yes & 275 & $(84.1)$ & 52 & $(15.9)$ & 1.00 (ref) & \multirow{2}{*}{0.875} \\
\hline No & 125 & $(83.3)$ & 25 & $(16.7)$ & $1.044(0.611-1.783)$ & \\
\hline \multicolumn{7}{|c|}{$\begin{array}{l}\text { Vegetables, salads } \\
\text { and fruit juice intake }\end{array}$} \\
\hline Frequent & 274 & $(83.5)$ & 54 & $(16.5)$ & $0.690(0.411-1.160)$ & \multirow[t]{2}{*}{0.161} \\
\hline Infrequent & 126 & $(84.6)$ & 23 & $(15.4)$ & 1.00 (ref) & \\
\hline \multicolumn{6}{|l|}{$\begin{array}{l}\text { Crisps and cake } \\
\text { intake }\end{array}$} & \multirow[t]{3}{*}{0.395} \\
\hline Frequent & 120 & $(82.2)$ & 26 & $(17.8)$ & $1.271(0.731-2.209)$ & \\
\hline Infrequent & 280 & $(86.4)$ & 51 & $(15.4)$ & $1.00($ ref) & \\
\hline \multicolumn{7}{|c|}{$\begin{array}{l}\text { Energy providing and } \\
\text { soft drinks intake }\end{array}$} \\
\hline Frequent & 231 & $(83.1)$ & 47 & $(16.9)$ & $1.128(0.664-1.916)$ & \multirow[t]{2}{*}{0.656} \\
\hline Infrequent & 169 & $(84.9)$ & 30 & $(15.1)$ & 1.00 (ref) & \\
\hline \multicolumn{7}{|l|}{$\begin{array}{l}\text { Milk and dairy } \\
\text { products intake }\end{array}$} \\
\hline Frequent & 228 & (83.8) & 44 & $(16.2)$ & $0.967(0.581-1.609)$ & \multirow[t]{2}{*}{0.896} \\
\hline Infrequent & 172 & $(83.9)$ & 33 & $(16.1)$ & 1.00 (ref) & \\
\hline \multicolumn{7}{|c|}{$\begin{array}{l}{ }^{*} \text { Including overweight } \\
{ }^{* *} \text { Odds ratio } \\
{ }^{* * *} \text { Consumes every day or more daily } \\
{ }^{* * * *} \text { Consumes once in awhile or does not consume at all. }\end{array}$} \\
\hline
\end{tabular}


Regarding association of life style practices of students with overweight and obesity, only the number of sleeping hours/ night was significantly associated with overweight and obesity, where sleeping less than 6 hours and between 6 and 8 hours were significantly associated with overweight and obesity $(P=0.004$ and 0.001 , respectively). These findings are shown in Table 3. Regarding association of life style practices of students with overweight and obesity, only the number of sleeping hours/night was significantly associated with overweight and obesity, where sleeping less than 6 hours and between 6 and 8 hours were significantly associated with overweight and obesity $(P=0.004$ and 0.001, respectively). These findings are shown in Table 3.

Table 3: Association between body mass index categories and life style characters of the students, using binary logistic regression.

\begin{tabular}{|c|c|c|c|c|c|c|}
\hline \multirow[t]{2}{*}{ Variables } & \multicolumn{2}{|c|}{$\begin{array}{l}\text { Non- obese } \\
(400)\end{array}$} & \multicolumn{2}{|c|}{$\begin{array}{l}\text { Obese* }^{*} \\
(77)\end{array}$} & \multirow[t]{2}{*}{ OR $(95 \% \mathrm{Cl})$} & \multirow[t]{2}{*}{$P$ value } \\
\hline & No. & $(\%)$ & No. & $(\%)$ & & \\
\hline \multicolumn{7}{|l|}{ Exercise } \\
\hline Yes & 255 & $(85.6)$ & 43 & $(14.4)$ & 1.00 (ref) & \\
\hline No & 145 & $(81.0)$ & 34 & $(19.0)$ & $0.719(0.439-1.178)$ & 0.191 \\
\hline \multicolumn{7}{|c|}{ Exercise hours/day } \\
\hline$<2$ hours & 160 & $(84.3)$ & 30 & $(15.7)$ & $1.376(0.685-2.766)$ & 0.370 \\
\hline$>2$ hours & 95 & $(88.1)$ & 13 & $(11.9)$ & 1.00 (ref) & \\
\hline \multicolumn{7}{|c|}{$\begin{array}{l}\text { Hours watching } \\
\text { TV and satellite }\end{array}$} \\
\hline$<2$ hours & 75 & $(87.2)$ & 11 & $(12.8)$ & 1.00 (ref) & \\
\hline$>2$ hours & 324 & $(83.1)$ & 66 & $(16.9)$ & $0.720(0.363-1.430)$ & 0.384 \\
\hline \multicolumn{7}{|c|}{ Sleeping hours/day } \\
\hline$<6$ hours & 65 & $(78.3)$ & 18 & $(21.7)$ & $2.828(1.400-5.712)$ & 0.004 \\
\hline $6-8$ hours & 141 & $(77.9)$ & 40 & $(22.1)$ & $2.897(1.610-5.213)$ & 0.001 \\
\hline$>8$ hours & 194 & $(91.1)$ & 19 & $(8.9)$ & 1.00 (ref) & \\
\hline \multicolumn{7}{|l|}{ Smoking } \\
\hline Yes & 19 & $(79.2)$ & 5 & $(20.8)$ & $1.393(0.504-3.850)$ & 0.523 \\
\hline No & 381 & $(84.1)$ & 72 & $(15.9)$ & 1.00 (ref) & \\
\hline
\end{tabular}

${ }^{*}$ Including overweight 


\section{Discussion}

The dietary habits of children and adolescents have been scrutinized as never before over the last few years and the need to monitor eating habits among young people has intensified in recent years due to the growing epidemic of overweight status worldwide., ${ }^{9,10}$ The present study, which was carried out on intermediate and secondary school students had provided results with implications for designing programs for health promotion and improvement in nutritional habits for adolescents. As far as BMI is concerned, most of the students were of normal weight range values. Although the prevalence of overweight and obese subjects was very low in both sexes, it was significantly higher in females than males. This might be due to the nature of geographical area and composition of the population with no entertainment facilities for females, which oblige them to spend more hours indoors. Studies in Iraq, Algeria, and Tunisia had shown similar findings. ${ }^{5,6,11}$ However, studies in Lebanon, ${ }^{3}$ Italy, ${ }^{12}$ and India ${ }^{13}$ revealed thatthe prevalence of overweight and obesity was more common among males than females. In addition, obesity was more common among those less than 18 years than among those 18 years and more. A possible explanation behind this finding is that older age groups have more access to different recreational facilities outside the home with more opportunities for exercise. However, a study in India showed that as age advances, there is a significant increase in the prevalence of obesity. ${ }^{13}$ Studies in Pakistan ${ }^{14}$ and Brazil ${ }^{15}$ reported that younger age presented an increased risk of obesity. All reported eating habits including breakfast, lunch, fried food, vegetables, salads and fruit juice intake, in addition to intake of crisps and cakes, energy providing drinks, soft drinks, and of milk and dairy products, have no significant association with overweight and obesity. The possibility that students are usually skip breakfast and lunch, and have an easy access to unhealthy foods, which is a common fact in most communities, might be the explanation behind this finding. In addition the nature of such agricultural communities in which children are helping their parents in manual works, farming and animal rearing in addition to other local factors related to the home environment. These results are not consistent with that of a study in India, where prevalence of obesity was higher among those consuming fried foods, soft drinks regularly and in those who do not exercise regularly. ${ }^{14}$ Regarding association of life style characters of students with obesity; only the number of sleeping hours/ night was significantly associated with obesity, where sleeping less than six hours and between six and eight hours was significantly associated with obesity. This might be due to the fact that those slept less than 8 hours/night have more access to ready- made foods and have more time for eating. A study in the USA reported that sleep duration was associated with increased likelihood of obesity among females, while there was no significant association between obesity and sleep duration in males. ${ }^{16}$ Another study in USA had showed that for each hour increase in sleep, the risk of overweight/obesity was reduced on average by $9 \% .{ }^{17} \mathrm{~A}$ study in Saudi Arabia reported that high prevalence of short sleep duration among Saudi adolescents (15-19 years) was significantly associated with increased risk of overweight and obesity. ${ }^{18}$ While there is experimental evidence for metabolic pathways whereby shortened sleep duration might lead to obesity. Sleep restriction in healthy adults resulted in decreased leptin levels, consequently results in decreased satiety and increased ghrelin levels, which leads to increased appetite. Alterations in these hormone levels may lead to increased caloric intake and subsequently more weight gain among persons with shortened sleep duration. ${ }^{16}$

\section{Conclusion}

The prevalence of overweight and obesity 
among the study sample was low and there was no significant association with the eating habits and life-style practices, apart from those sleeping less than eight hours/nigh. The finding could help health educators to develop proper nutritionrelated education programs that promote healthy food choices, good eating habits and better life style practices.

\section{Conflicts of interest}

The authors report no conflicts of interest.

\section{References}

1. Al-Rethaiaa AS, Fahmy AA, Al-Shwaiyat NM. Obesity and eating habits among college students in Saudi Arabia: A cross- sectional study. Nutr J 2010; 9(39):2-10.

2. Turconi G , Guarcello M, Maccarini L, Cignoli F, Setti S, Bazzano R, et al. Eating habits, behaviors, physical activity, nutritional, food safety knowledge, and beliefs in an adolescent Italian population. J Am CollNutr 2008; 27 (1):31-43.

3. Yahia N, Achkar A, Abdallah A, Rizk S. Eating habits and obesity among Lebanese university students. Nutr J 2008; 7:(32):1-6.

4. Yuasa K, Sei M, Takeda E, Ewis AA, Munakata $\mathrm{H}$, Onishi $\mathrm{C}$, et al. Effects of lifestyle habits and eating meals together with the family on the prevalence of obesity among school children in Tokushima, Japan: A cross-sectional questionnaire- based survey.J Med Invest 2008; 55(1-2):71-7.

5. Sadiq MA. Prevalence of obesity in secondary schools females in Al-Karkh side of Baghdad city. Middle East Journal of Family Medicine 2013; 8(5):30-4.

6. Kadhim MJ. Childhood obesity in Iraq: prevalence and possible risk factors. Ann Saudi Med 2005; 25 (5):389-93.

7. Youth Risk Behaviour Survey. Centres for Disease Control and Prevention/Standard Questionnaire 2013; 1-35.

8. WHO. Physical status: The use and interpretation of anthropometry. Geneva: WHO; 1995. WHO Technical Report Series.

9. Lamb L. A Glimmer of light: Eating habits of children in Liverpool. Liverpool: Liverpool Education, Library and Sports Services; 2013.

10. Zaborskis A, Lagunaite R, Busha R, Lubiene J. Trend in eating habits among Lithuanian school aged children in context of social inequality: three cross-sectional surveys 2002, 2006 and 2010. BMC Public Health 2012; 12(52):1-12.

11. Atek M, Traissac $P$, El Ati J, Laid $Y$, Skhiri HA, Duvernay SE, et al. Obesity and association with area of residence, gender and socio-economic factors in Algerian and Tunisian adults. PLOS ONE 2013; 8(10):1-10.
12.Calabrese G, Maj M, Testa M, Fioramonti E, Ros si F. Study of the eating habits of the students attending the first 2 years at high school in Italy. Mediterr J NutrMetab 2013; 6:143-50.

13. Kumar KM, Prashanth K, Baby KE, Rao KR, Kumarkrishna B, Hegde K, et al. Prevalence of obesity among high school children in Dakshina Kannada and Udupi districts. NUJHS 2011; I (4):16-20.14. 14. Ahmed J, Laghari A, Naseer M, Mehraj V. Prevalence of and factors associated with obesity among Pakistani schoolchildren: a school-based, cross-sectional study. East Mediterr Health J 2013; 19(3):242-7.

15. Triches RM, Giugliani ERJ. Obesity, eating habits and nutritional knowledge among school children. Rev SaudePublica 2005; 39(4):1-7.

16. Lowry R, Eaton DK, Foti K, McKnight-Eily L, Perry G, Galuska DA. Association of sleep duration with obesity among US high school students. Journal of Obesity 2012; 2012: 1-9.

17. Chen $X$, Beydoun MA, Wang $Y$. Is sleep duration associated with childhood obesity? A systematic review and Meta-analysis. Obesity 2008; 16: 265-74.

18. Al-Hazzaa HM, Musaiger AO, Abahussain NA, Al-Sobaye HI, Qahwaji DM. Prevalence of short sleep duration and its association with obesity among adolescents 15- to 19-year olds: A crosssectional study from three major cities in Saudi Arabia. Ann Thorac Med 2012; 7(3):133-9. 